\title{
Trabalhonecessário
}

\section{LUTA DE CLASSES E A QUESTÃO DA DIVERSIDADE HUMANA: DEBATE ATUAL E PERSPECTIVAS POLÍTICO-TEÓRICAS ${ }^{12}$}

Silvana Mara de Morais dos Santos ${ }^{3}$

\section{Resumo}

O artigo analisa a concepção de diversidade humana em uma perspectiva de totalidade, elegendo o materialismo histórico como referencial teórico. Tem como objetivo realizar a crítica às perspectivas economicistas e politicistas de entendimento da diversidade e afirmar uma concepção de diversidade como característica do processo de individuação e sua necessária relação com a sociabilidade e as determinações oriundas da luta de classes.

Palavras-chave: Diversidade Humana; Esquerda; Luta de Classes

\section{LUCHA DE CLASES Y LA CUESTIÓN DE LA DIVERSIDAD HUMANA: DEBATE ACTUAL Y PERSPECTIVAS POLÍTICAS-TEÓRICAS}

\section{Resumen}

El artículo analiza la concepción de diversidad humana en una perspectiva de totalidad, eligiendo el materialismo histórico como referencial teórico. Tiene como objetivo realizar la crítica a las perspectivas economicistas y politicistas de entendimiento de la diversidad y afirmar una concepción de diversidad como característica del proceso de individuación y su necesaria relación con la sociabilidad y las determinaciones oriundas de la lucha de clases.

Palabras clave: Diversidad Humana; izquierda; Lucha de Clases

\section{CLASS FIGHTING AND THE QUESTION OF HUMAN DIVERSITY: CURRENT DEBATE AND POLITICAL-THEORETICAL PERSPECTIVES}

\section{Abstract}

The article analyzes the conception of human diversity from a perspective of totality, choosing historical materialism as a theoretical reference. Its purpose is to critique the economist and politicist perspectives of understanding diversity and to affirm a conception of diversity as a characteristic of the process of individuation and its necessary relation to sociability and determinations derived from the class struggle.

Keywords: Human Diversity; Left; Class struggle.

1 DOI: https://doi.org/10.22409/tn.17i32.p28303

${ }^{2}$ Artigo revisado a partir da palestra proferida no IV Intercrítica realizado no dia 27/11/2018 em Natal/RN. A mesa foi coordenada pelo Profo ${ }^{\circ}$ José Mateus do Nascimento. Agradeço ao Profo Dante Moura (IFRN) e a Prof.Lia Tiriba (UFF).

${ }^{3}$ Doutora em Serviço Social, professora do Departamento e do Programa de Pós-Graduação em Serviço Social da Universidade Federal do Rio Grande do Norte (UFRN). E-mail: sillmorais@gmail.com 


\section{Introdução}

O IV Intercrítica - Intercâmbio Nacional de Grupos de Pesquisa em Trabalho e Educação - se realiza em um momento difícil de avanço do conservadorismo no Brasil e no mundo, que se expressa na radicalização das classes dominantes para a superexploração da força de trabalho, com destruição de direitos e profundo retrocesso no respeito à diversidade humana. "Veloz e furioso", o sistema do capital se empenha para assegurar sua auto reprodução, orientada para acumulação e reprodução ampliada, sem considerar, em tempos de crise estrutural ${ }^{3}$, conquistas históricas e civilizatórias da classe trabalhadora em sua heterogeneidade e diversidade. Nas particularidades da realidade brasileira, a vitória das forças políticas de direita representa explícito avanço da combinação entre política reacionária, fundamentalismo religioso e moralismo. Isto mostra os grandes desafios que temos para assegurar reflexão crítica e práticas na perspectiva emancipatória. $A$ interação acadêmico-política se torna ainda mais fundamental e o INTERCRÍTICA contribui nesta perspectiva.

Nosso objetivo, portanto, nos limites desse artigo, destina-se à discussão de quatro questões fundamentais: (1) os limites do entendimento da diversidade em determinadas concepções teórico-políticas no campo da esquerda; (2) Qual a concepção de diversidade que estamos defendendo; (3) Algumas polêmicas que gravitam em torno do tema da diversidade humana e sua relação com a luta de classes e (4) lições históricas e desafios que reflitam por que é imprescindível que um projeto de resistência na perspectiva da transformação social contemple a diversidade humana.

Em face desse objetivo não abordaremos as diferentes expressões da diversidade, que aglutina, dentre outras, a questão do feminismo, das relações sociais de sexo/gênero, de raça, étnicas e de identidade de gênero. Partiremos da concepção de diversidade humana em seu aspecto teórico-histórico, que envolve e, ao mesmo tempo, vai além das expressões que particularizam dimensões da diversidade.

\footnotetext{
${ }^{3}$ Para análise da crise estrutural do capital e sua diferença ontológica para as crises cíclicas, ver MĖSZÁROS (2002).
} 
Em termos teórico-metodológico, buscamos extrair, do legado marxiano e da tradição marxista, indicações que possibilitem o entendimento dessa complexa relação entre a luta de classes e a diversidade. Ademais, o tema soma-se a um conjunto de reflexões que visam, também, promover um processo de resistência teórico-política em tempos de avanço de um certo tipo de irracionalismo e da disseminação de uma cultura política fundada na defesa do anti conhecimento, do pragmatismo e do preconceito.

A produção do conhecimento em sua densidade histórica tem sido bastante desvalorizada nessa conjuntura. As contribuições para o entendimento da complexidade da realidade, por meio da crítica qualificada da vida cotidiana, do ethos burguês, do papel do Estado, das políticas sociais e dos limites das instituições na sociedade capitalista parece não ter valor nenhum para determinadas forças políticas conservadoras. O pior é que estas forças incidem ideologicamente sobre amplos segmentos da população brasileira e da classe trabalhadora, em particular. Por estas razões, não há dúvida quanto à relevância acadêmica, política e social da temática e sua atualidade no Brasil contemporâneo.

\section{A Diversidade no labirinto entre o economicismo e o politicismo}

No final dos anos 1960 em nível mundial e, no Brasil, um pouco mais adiante, década de 1980, considerando o largo período da ditadura civil-militar, um conjunto de sujeitos coletivos anunciaram a necessidade histórica quanto ao reconhecimento da diversidade, levantaram suas bandeiras e questões, deixando vir à tona processos de auto-organização, principalmente, por meio de movimentos sociais e diferentes grupos, dentre outros, da juventude, das mulheres, dos indígenas, de lésbicas, gays, bissexuais, travestis, transexuais (LGBT), da população negra nas lutas anti raciais e de grupos em defesa da questão socioambiental.

Estes movimentos sociais e demais coletivos provocaram uma série de questionamentos ao evidenciarem, na trilha dos movimentos feministas, que "o pessoal é político" e que expressões da diversidade humana relacionadas à sexualidade, gênero, à raça/etnia significava, na vida cotidiana, um perigoso caminho de opressão. Invisibilizados na vida social e submetidos às práticas de humilhação, violência e violação de direitos, os indivíduos, por apresentarem um 
jeito de ser e viver de forma diversa aos padrões e sistemas hegemônicos, se tornaram alvo preferencial da discriminação e do preconceito. $O$ inusitado foi que estas formas de opressão, historicamente reproduzidas em ambientes fundados no ideário conservador, tão funcional às classes dominantes, pareciam permeáveis, também, às forças políticas no campo das esquerdas.

Embora que a relação entre esquerda e diversidade, em suas diferentes matrizes, no plano internacional e nacional seja uma questão polêmica de longa data ${ }^{4}$, aqui faremos referência a um período mais recente, as últimas décadas do século XX. Sobre isso é pertinente a afirmação de Rodrigues (2011, p.26):

[...] é preciso ressaltar que mesmo os movimentos de esquerda, socialistas, dos trabalhadores, sempre tiveram uma dificuldade muito grande para incorporar alguns temas, como os direitos das mulheres, o combate ao racismo, e especialmente os chamados direitos sexuais. [...] sempre foram uma questão menor (como no caso das mulheres) ou simplesmente uma não questão (no caso dos homossexuais).

A presença especialmente dos movimentos feministas, LGBT, antirracistas, chamou atenção para o fato de que transformar as relações sociais vigentes era bem mais complexo do que os processos até então desenvolvidos de investimento na organização política da classe trabalhadora e na formação da sua consciência de classe. Até porque, valendo-nos de uma abordagem de totalidade na apreensão da realidade, podemos nos questionar: a auto-organização desses sujeitos significa, necessariamente, apostar na lógica da fragmentação, constituindo-se em obstáculo à formação da consciência de classe? Voltaremos a esta questão mais adiante.

As perspectivas teórico-políticas divergentes, que historicamente permearam as discussões entre as forças de esquerda, se voltaram para inquietações mais contundentes referentes à necessidade de aprofundar diferenças entre lutas gerais e lutas específicas; ao questionamento quanto à ameaça que o apelo político à diversidade provocava, por fragmentar a classe trabalhadora e descentralizá-la da construção de um projeto revolucionário anticapitalista. $E$, na base dessas polêmicas, emergia, com vitalidade, elementos de crítica ao marxismo, por supostamente desconsiderar a relevância do cotidiano, da diversidade e da

\footnotetext{
${ }^{4}$ Podemos indicar as discussões que permeiam as reivindicações e lutas feministas por ocasião da Revolução Russa, a exemplo: SCHENEIDER (Org.) (2017) e GOLDMAN (2014) bem como as dificuldades da esquerda de tomar para si a agenda de combate ao racismo e defesa das estratégias anti-raciais e LGBTfóbicas.
} 
individualidade/subjetividade ${ }^{5}$. Digo supostamente, porque discordo dessa crítica e espero, que ao abordar o conjunto das questões propostas e, notadamente, a relação entre diversidade e luta de classes possa explicitar tal discordância e mostrar a pertinência da perspectiva de totalidade na análise da vida social para apreensão dos complexos sociais da individualidade e da sociabilidade.

De modo mais abstrato, sem adentrarmos para as diferenças internas no universo das forças políticas, podemos afirmar que, no campo da direita, jamais houve acolhimento para a diversidade humana. A defesa da propriedade privada; de valores morais conservadores que, via de regra, se transmutam em moralismo e defesa da família tradicional, fundada no casamento monogâmico integram sua concepção de mundo e plataforma política. Assim, era plausível a expectativa dos movimentos sociais de que as forças de esquerda dialogassem e assumissem as reivindicações da diversidade em sua agenda política.

A realidade, no entanto, mostrou que a relação entre as forças de esquerda e a diversidade demanda um longo caminho de construção, que se apresenta, na maioria das vezes, bastante tortuoso. Obviamente que existiram forças de esquerda que conseguiram incorporar com mais capacidade política de articulação e criticidade às demandas da diversidade, mas a tendência majoritária foi 0 predomínio de uma leitura determinista/economicista da realidade. Tal leitura disseminou com muita força ideológica que a agenda em defesa da diversidade significava um entrave à formação da consciência de classe e que representava um certo atraso, decorrente de possíveis capitulações de militantes e organizações políticas ao universo pequeno-burguês. ${ }^{6} \mathrm{~A}$ ideia prevalecente é de que as formas de opressão, além de completamente apartadas dos processos de exploração da força de trabalho, tenderiam a se resolver de forma "mágica" com a superação do sistema do capital.

\footnotetext{
${ }^{5}$ Para a crítica da crítica ao marxismo em face de uma suposta incapacidade teórico-metodológica para apreensão da diversidade humana e em particular da diversidade sexual, Cf. SANTOS (2018).

${ }^{6}$ GREEN (2000, P. 433) ao resgatar a trajetória da homossexualidade masculina no Brasil do século XX, afirma que em 1979 em um debate público na Universidade de São Paulo "as discussões que se seguiram às apresentações dos oradores foram acaloradas, à medida que os ataques e contraataques entre os representantes dos grupos estudantis de esquerda e defensores dos interesses de gays e lésbicas cruzavam a sala. Pela primeira vez, as lésbicas podiam falar abertamente em público sobre a discriminação que sofriam. Os estudantes gays se queixavam de que a esquerda brasileira era homofóbica".
} 
A crítica a esta leitura economicista teve como principal alvo o marxismo. Acusado de se constituir como uma concepção teórico-política que considerava todas as dimensões da vida social como epifenômenos da economia, além de desvalorizar os complexos sociais do direito, da cultura e da individualidade e simplificar a construção de um projeto emancipatório, o marxismo foi, então, amplamente descartado no universo de boa parte das esquerdas, incluindo alguns partidos políticos, movimentos sociais e intelectuais historicamente identificados nesse campo político.

Em relação ao tratamento dado à diversidade, o resultado foi que as forças economicistas, para se diferenciar e criticar a denominada "nova esquerda" que emergia mundialmente, reforçaram, sem atenção nenhuma à vida concreta, a instauração de um fosso ainda mais abissal entre as lutas gerais e específicas; entre economia e cultura; indivíduo e classe social e entre vida subjetiva e militância política.

Consideramos que a crítica a esta tendência economicista foi e é pertinente. O problema é que a crítica ao determinismo ganhou o mesmo sentido de crítica ao marxismo. Houve uma generalização absurda quanto à inviabilidade teórica do marxismo para apreensão da realidade contemporânea. Renegado a uma teoria do século XIX, estava decretado pelas novas forças de esquerda, a impossibilidade de entendimento da realidade e da diversidade a partir de uma perspectiva de totalidade.

Esses aspectos característicos de uma visão reducionista da vida social foram atribuídos, equivocadamente, ao legado de Marx e se disseminaram, com intensidade, no seio do movimento operário e de suas organizações. Caracterizado enquanto um marxismo vulgar, de caráter positivista, os postulados da II Internacional erigem como a específica contribuição teórica de Marx - uma concepção simultaneamente reducionista e indevidamente generalizadora. Reducionista enquanto dissolve as concretas mediações e determinações histórico-sociais com a sua inserção num esquema lógico-interpretativo[...] e indevidamente generalizadora enquanto impõe esse esquema à realidade como um todo [...] (NETTO, 1981, p.20).

Se, para este tipo de esquerda, o marxismo não apresentava fundamentos capazes de favorecer o entendimento da sociedade contemporânea e da diversidade dos indivíduos, era preciso, então, buscar fontes teórico-políticas que pudessem incorporar o direito à diferença como algo fundamental. Amplos 
segmentos de esquerda romperam com o marxismo e abraçaram uma perspectiva de análise da realidade que priorizava análises do cotidiano, da política, dos direitos humanos, da individualidade e da cultura. Temáticas indiscutivelmente relevantes. $\mathrm{O}$ grande obstáculo é que prevaleceu nessas análises a dissociação entre cotidiano e relações sociais no mundo capitalista. Não negaram a existência do capitalismo, mas não estabeleciam conexões e mediações históricas entre os fenômenos analisados e as determinações objetivas/subjetivas próprias do sistema do capital. Sobressaiu, portanto, a tendência de criticar o economicismo pelo viés de uma análise fragmentada, de caráter politicista na apreensão da realidade e, no limite, funcional à lógica dominante, em face da opção ideológica de viver e mudar as relações cotidianas, sem levar em consideração a historicidade dos processos reais que colocavam impedimentos à vigência da liberdade e da igualdade substantivas, nos termos de Mèszáros (2002).

É inegável as contribuições dadas pela esquerda não determinista. A agenda da diversidade ganhou visibilidade, com processos de politização da vida cotidiana e de inúmeras formas de opressão. A auto-organização de novos sujeitos coletivos foi um dos aspectos fundamentais para as conquistas obtidas, que, embora aquém das necessidades reais, são importantes. Ademais, por meio da visibilidade social e política que alcançaram no enfrentamento da violação de direitos, pautaram, implicaram e exigiram diante das reivindicações em defesa da diversidade, respostas do Estado, por meio de algumas iniciativas no campo das políticas públicas e sociais, destacando-se ações nas áreas da educação, saúde e cultura.

No entanto, a direção social atribuída para determinadas reivindicações se revelou insuficiente e, por vezes, equivocada ao disseminar ou naturalizar, por exemplo, a ideologia do fim das classes sociais e da impossibilidade de a classe trabalhadora construir um projeto político anticapitalista. A prevalência de uma abordagem centrada na perspectiva da subjetividade ${ }^{7}$ em detrimento da totalidade social definiu horizontes políticos e espaços prioritários de atuação.

As consequências deste ponto de vista da subjetividade para a reflexão acerca de qualquer fenômeno social são extremamente danosas. Se a realidade social não é uma totalidade articulada, mas uma coleção de fragmentos; se a fragmentação não é um produto histórico-social, mas uma determinação natural da realidade; se a nenhuma das partes da realidade pertence o caráter de matriz de

\footnotetext{
${ }^{7}$ Cf. TONET (2013).
} 
todas as outras; se inexiste um fio condutor que perpasse e dê unidade ao conjunto da realidade social; se não existe história, mas apenas histórias; se não existe gênero humano, mas apenas grupos sociais diferentes e, no limite, indivíduos singulares; se as categorias são meros construtos mentais e não determinações da própria realidade; se não existe verdade, mas apenas verdades; se o conceito de realidade nada mais é que uma construção mental; se perdido, rejeitado ou nunca efetivamente compreendido o fio condutor que articula todo o processo social - a autoconstrução do homem pelo homem a partir do trabalho - só resta ao sujeito interpretar e "transformar" o mundo segundo critérios por ele mesmo estabelecidos (TONET, 2013.p.63-64).

Assim, o horizonte da transformação social foi cedendo lugar para o ideário da igualdade de oportunidade ${ }^{8}$, como princípio orientador da organização coletiva de boa parte dos sujeitos coletivos e o parlamento e o judiciário se tornaram os espaços, por excelência, da disputa política, em detrimento das lutas sociais para além da legalidade burguesa.

Ressalte-se aqui que as lutas por igualdade de oportunidade são importantes, mas precisam ser bem articuladas e trabalhadas para não criar ilusões de que há condições reais de superar sexismo, LGBTIfobia $^{9}$, racismo, exclusivamente por meio da legalidade, sem transformar o sistema capitalista, hetero-patriarcal-racista. Sobre o caráter ilusório da dimensão jurídico-política vale a seguinte reflexão:

a ilusão jurídica é uma ilusão não porque afirma o impacto das ideias
legais sobre os processos materiais, mas porque o faz ignorando as
mediações materiais necessárias que tornam esse impacto
totalmente possível. As leis não emanam simplesmente da vontade
livre dos indivíduos, mas do processo total da vida e das realidades
institucionais do desenvolvimento social-dinâmico, dos quais as
determinações volitivas dos indivíduos são parte integrante
(MĖSZÁROS, 2008, p.163).

A rigor, podemos examinar que o solo histórico sinalizava a crise do capital que despontou a partir da década de 1970, mas que nos anos 1980 foi subtraída da análise de boa parte dos movimentos sociais e de outras organizações de esquerda. Uma análise criteriosa evidenciaria os limites estruturais para a efetividade real da igualdade, da liberdade e da diversidade no mundo burguês. Afinal, a tendência histórica do capitalismo desde suas origens foi de homogeneizar culturas, modos de ser, viver e sentir. E, neste sentido, desconsiderar a diversidade humana ou incluí-la

\footnotetext{
${ }^{8}$ Para a crítica aos limites da igualdade de oportunidade, Cf. SANTOS (2010).

${ }^{9}$ Lésbicas, gays, bissexuais, travestis, transexuais e intersexuais (LGBTI).
} 
mediante a vigência de uma relação meramente formal e/ou mercantil, sem atenção programática e política às necessidades e reivindicações no campo do feminismo, das lutas antirracistas e em defesa da diversidade sexual, exceto quando for possível transformá-las em nichos lucrativos. É necessário considerar, ainda, os limites que esta crise estrutural gera sobre os ganhos da emancipação política. Ou seja, a tendência contemporânea no mundo do capital é a regressão dos direitos.

Em síntese, para os economicistas, as reivindicações no campo da diversidade eram entendidas como lutas de caráter e relevância social inferiores, necessariamente fragmentadas e ancoradas na lógica de um pensamento e prática política completamente funcionais à reprodução do sistema do capital. Para os críticos do determinismo que formaram um novo tipo de esquerda, o momento histórico sinalizava para uma espécie de admirável mundo novo, que colocava em cena a pluralidade de atores, linguagens e um forte apelo para pensar a subjetividade dos indivíduos e a realidade em sua imediaticidade. Ocorre uma espécie de autonomização do indivíduo, da cultura, da política e do direito em face das determinações objetivas, abrindo caminho para consolidar concepções politicistas e culturalistas. E o grande equívoco teórico-político de entendimento da sociedade civil como campo exclusivo da atuação das forças populares resultou em um profundo distanciamento da realidade concreta da sociedade capitalista e da luta de classes como motor da história.

O duelo entre economicismo e politicismo marca as concepções teóricopolíticas no campo da esquerda. Ambas concepções deixaram escapar o importante legado do pensamento marxiano e de autores da tradição marxista, a exemplo de Gramsci e Lukács, além de produções feministas, incluindo aquelas referentes à questão racial ${ }^{10}$, que tematizaram a necessidade da crítica ao capitalismo e relevância das lutas pelo socialismo. Apesar da importante crítica realizada por parte da esquerda ao determinismo, os fundamentos teórico-metodológicos utilizados por uma esquerda de caráter politicista reforçou processos de fragmentação das reivindicações, dos sujeitos políticos e a ilusão da colaboração entre as classes sociais ou no limite, sua extinção em plena vigência do capitalismo, assim como também, o fim das ideologias e a negação da centralidade do trabalho na vida social para afirmação da centralidade da linguagem e da política. As análises de caráter

\footnotetext{
${ }^{10}$ Cf. DAVIS (2016).
} 
economicista, politicista e culturalista apresentam, portanto, frágil nível de complexidade na apreensão do real, ainda que não fossem estas as intencionalidades dos sujeitos individuais e coletivos.

\section{Diversidade Humana pressupõe igualdade substantiva na vida social}

Feitas estas observações críticas ao entendimento da diversidade a partir das concepções economicistas e politicistas, destacaremos elementos reflexivos que possibilitem apreendê-la em uma perspectiva de totalidade.

A diversidade é, portanto, uma característica do indivíduo, que deve ser entendido como ser histórico em suas relações concretas de existência. Aí reside o caráter social da individualidade e a razão da diversidade ser apreendida na relação singular/humano-genérico. Neste sentido, abrange as expressões das relações sociais de sexo/gênero, étnico-raciais, de identidade de gênero, mas vai além. Tratase da concepção de que todos os indivíduos são sociais, históricos e diversos. Com isto podemos afirmar a existência da diversidade Humana, aqui entendida como característica que se apresenta no processo de individuação, frente às exigências postas na divisão social do trabalho e no desenvolvimento do gênero humano (SANTOS, 2008).

Na perspectiva de totalidade é vital entender o trabalho como fundante do ser social e um conjunto articulado de mediações históricas que possibilitam apreender que "[...] a personalidade resulta da elevação das capacidades humanas como consequência indireta do desenvolvimento do processo de trabalho e, mesmo que por muitas mediações, tem sempre o trabalho como sua base ontológica fundamental" (COSTA, 2007, p. 19).

A diversidade como dimensão constitutiva da individualidade se aprofunda e se complexifica mediante o desenvolvimento histórico. Assim, as lutas contemporâneas que marcaram as últimas décadas do século $X X$ e se atualizam nos dias atuais não traduzem toda a expressão da diversidade humana. São expressões significativas, com caráter político-estrutural, constituintes da individualidade ao lado de outras dimensões que conformam a singularidade. Pensar o indivíduo social como ser diverso pressupõe admitir que há modos singulares de apropriação do mundo. O tempo histórico, a inserção objetiva e posicionamento 
subjetivo de classe, as escolhas pessoais, profissionais e políticas são determinações que incidem na formação da individualidade. Se pensarmos, por exemplo, indivíduos que vivem em uma mesma época; tendo os mesmos acessos institucionais (educação, saúde, cultura, lazer, dentre outros); mesma orientação sexual, identidade de gênero, raça, geração e escolhas ideológicas, mesmo assim são seres diversos. Com isso estamos afirmando que as relações sociais de classe/sexo/raça são dimensões politicamente estruturantes da diversidade humana, mas além de existir outras expressões, o indivíduo se faz diverso no processo de apropriação da sua existência em um determinado tempo histórico. As lutas sociais feministas, anti-raciais e em defesa da diversidade sexual foram fundamentais para pautar politicamente a diversidade humana, pois:

por intermédio dessas lutas, os indivíduos politizam a diversidade, sendo esta algo que é próprio da individualidade, que se expressa e se altera no desenvolvimento das forças produtivas, considerando as objetivações/exteriorização do ser social que demandam respostas cada vez mais complexas" (SANTOS, 2017:14).

A concepção de diversidade humana, possibilita que suas diferentes dimensões e expressões não sejam caracterizadas como recortes, marcadores sociais, estilos de vida e atributos no modo de se vestir, falar e se expressar. Em uma perspectiva de totalidade, assume um caráter bem mais complexo. Integra o processo de individuação, guarda relação de determinação recíproca com a sociabilidade e explicita o carecimento radical de cada indivíduo que, para assegurar o atendimento de suas necessidades necessita da produção do outro. Isto vale para as condições objetivas e subjetivas. Assim, "pela dimensão da diversidade, os indivíduos revelam singularidades, apresentam diferenças em seu modo de ser, de se apropriar, de se adaptar ou de buscar transformar as relações vigentes" (SANTOS, 2008, p.76).

$\mathrm{Na}$ sociedade capitalista, portanto, o indivíduo social, sob a perspectiva de sua inserção de classe vivencia a exploração da sua força de trabalho e o extravio e/ou empobrecimento da sua diversidade, que numa relação de consubstancialidade, expressa, também, as violações em face da raça/etnia, da sexualidade e da identidade de gênero. Isso porque os indivíduos são diversos e esta diversidade é um componente ontológico da sua individualidade. 


\section{Diversidade humana e sua relação com a luta de classes}

Tem sido frequente os questionamentos sobre o caráter fragmentário das lutas sociais e organizações políticas que atuam em defesa de expressões da diversidade. Para além da posição economicista/determinista, há uma preocupação real com o possível distanciamento da luta anticapitalista por sujeitos que se organizam em torno do feminismo, da diversidade sexual e do antirracismo. De modo tal que refletiremos sobre as seguintes questões: há uma contraposição teórico-política entre a luta anticapitalista e a luta em defesa da diversidade humana? qual o potencial da agenda da diversidade para fomentar consciência de classe? E, ainda: é possível o entendimento efetivo e profundo da realidade da desigualdade social sem considerar as reivindicações por direitos relacionados ao respeito e valorização da diversidade?

Como vimos são muitas as questões. Nossa intenção é problematizar estes questionamentos em conjunto para contribuir com a reflexão sobre a relevância social, política e humana da diversidade.

A consciência de classe não se forma de modo automático a partir da experiência cotidiana com a escassez de direitos e/ou pela vivência com a exploração da força de trabalho. Ao contrário disso, trata-se de um processo histórico, não linear, mas dinâmico e contraditório, permeado por descobertas subjetivas e objetivas sobre o funcionamento da sociedade e pela superação de concepções fundadas no ideário dominante de naturalização da desigualdade social. Um processo que é forjado no cotidiano marcado no front entre a força material da ideologia dominante e da alienação e a capacidade de fomentar uma concepção de mundo que articule ações de resistência no universo do conformismo e necessidade de lutar para alterar situações de exploração e de opressão. Pressupõe um movimento simultaneamente individual e coletivo e uma dimensão educativa, que não se limita à educação formal, embora esta seja importante. Isto significa o desenvolvimento de estratégias educativas e de formação política que possibilitem a apreensão das relações sociais que estruturam a sociedade capitalista, com o antagonismo entre as classes sociais e a propriedade privada. No centro disso tudo 
está o indivíduo em sua singularidade, fazendo e refazendo caminhos e aprimorando entendimentos, ora resistindo, ora adaptando-se, mas em movimento.

Diante disso, cabe questionar: há uma contraposição teórico-política entre a luta anticapitalista e a luta em defesa da diversidade humana? Defendemos que

não, pois o entendimento histórico da sociedade vigente exige a superação da concepção determinista de classe social, exilada das complexas condições objetivas e subjetivas e esvaziada de historicidade. Isto implica o conhecimento de quem são os indivíduos que compõem as classes sociais. Não se trata de seres abstratos, sem

vida, sonhos e buscas. São indivíduos concretos que precisam assegurar sua existência, que apresentam conflitos, que têm sexualidade, identidade de gênero, raça/etnia e que não conseguem escapar às determinações históricas do seu tempo.

O feminismo materialista deu contribuição significativa para historicizar estes

indivíduos, por meio da perspectiva da consubstancialidade-coextensividade que trata de forma indissociável as relações sociais de classe, sexo e raça. Contudo, segundo Kergoat (2010, p.100) esta concepção:

[...] não implica que tudo está vinculado a tudo; implica apenas uma forma de leitura da realidade social. É o entrecruzamento dinâmico e complexo do conjunto das relações sociais, cada uma imprimindo sua marca nas outras, ajustando-se às outras e construindo-se de maneira recíproca.

Podemos pensar, também, na perspectiva de "analisar estas contradições na condição de fundidas e enoveladas ou enlaçadas em um nó [...] no seio da nova realidade - novelo patriarcado-racismo-capitalismo - historicamente constituídos" (SAFFIOTI, 2004, p.125). ${ }^{11}$

Qual o potencial, então, da agenda da diversidade para fomentar consciência de classe? Sob a perspectiva de totalidade, classe não é um todo abstrato, dissociado do cotidiano dos indivíduos. É possível e necessário para atribuir densidade histórica à classe social, captar mediações no campo da diversidade humana, que favoreça o entendimento de que as determinações societárias não se constituem como uma escolha que podemos considerar ou não. Simplesmente não há nenhum fenômeno realmente existente que não sofra determinações e

\footnotetext{
${ }^{11}$ Sabemos que se instaurou uma polêmica entre as perspectivas da consubstancialidadecoextensividade e a perspectiva da interseccionalidade que não vamos desdobrar neste artigo. No entanto, ressaltamos a relevância de promover entre estas perspectivas um bom debate, que significa entendê-las, optar por um caminho de análise, mas sem que isto represente a aniquilação das contribuições de ambas à reflexão crítica da realidade.
} 
implicações das relações sociais vigentes e do modo como o hetero patriarcado e o racismo se tornaram funcionais à exploração e à dominação capitalista, alicerçando um sistema imperioso de dilaceramento da classe trabalhadora, em suas condições de vida e de trabalho.

Portanto, no sistema do capital que se estrutura mediante a propriedade privada dos meios de produção, a desigualdade social com a exploração da força de trabalho, combinada com inúmeras formas de opressão, temos determinações absolutamente contrárias à igualdade real, prevalecendo a igualdade meramente formal. O sistema vigente visa a acumulação em detrimento do atendimento das necessidades humanas, das mais básicas às mais complexas. Isto em si já seria suficiente para argumentar a inviabilidade teórico-política de cancelar as classes sociais na apreensão de qualquer fenômeno. Assim também como não é possível abstrair as relações sociais de sexo e de raça, posto que estas implicam dimensões da diversidade humana que além de serem constituintes da individualidade, representam, em uma sociedade desigual, um caminho fértil para aprofundar exploração e disseminar violação de direitos, formas de preconceito e de discriminação.

Do meu ponto de vista, é mais pertinente a pergunta inversa: como é possível consciência de classe sem consciência da diversidade humana? O mundo do trabalho não é um universo abstrato. Trabalhadores e trabalhadoras são históricos, sociais e diversos. Assim:

A classe como unidade na diversidade é especificada, ela própria, pela autonomia dos indivíduos que a compõem. Pensá-la como matriz única a partir da qual se constituem os indivíduos como sua repetição em nível do micro é não entendê-la como produto da multiplicidade desses indivíduos. A classe é, portanto, um coletivo de indivíduos. Coletivo que deve ser enriquecido pela história empírica desses indivíduos enquanto construtores das racionalidades sociais (DIAS, 1996, p.39).

Prevalece, assim, um real potencial da agenda da diversidade para fomentar consciência de classe. Tudo vai depender da direção social atribuída ao entendimento e às reivindicações dessa agenda. Da mesma forma, o entendimento efetivo e profundo da realidade da desigualdade social só é possível mediante o conhecimento da formação sócio histórica e devida apreensão de como historicamente o racismo e o hetero patriarcado se constituíram em relações que 
obstaculizaram o desenvolvimento da individualidade e o acesso à visibilidade social, ao trabalho com direitos e a viver sob a mira da reprodução cotidiana da violência. Não há como não considerar as reivindicações por direitos relacionados ao respeito e à valorização da diversidade, se a intenção for o conhecimento do real, em suas múltiplas determinações.

A diversidade, portanto, não se contrapõe à luta de classes, mas pode enriquecê-la, por possibilitar o conhecimento, resistência e luta contra o que explora, oprime, humilha e viola direitos em sua densidade histórica, pois são os indivíduos determinados, de carne e osso que dão concretude à classe social

\section{Lições históricas e desafios}

É vital em todos os momentos históricos buscarmos apreender as lições que nos sirvam de reflexão crítica para superar equívocos e/ou aprofundar estratégias que possibilitaram conquistas importantes relacionadas ao universo do trabalho e da diversidade humana. Destacamos as contribuições da perspectiva de totalidade na análise da vida social como lições históricas densas de significado e desafios.

Uma dessas lições é a certeza que não é possível ignorar a crise do capital neste momento contemporâneo, que gera um processo de regressão dos direitos que atinge mundialmente a classe trabalhadora como sujeito político coletivo e os indivíduos em suas singularidades. Com isso, submete os indivíduos a viver um cotidiano sem possibilidade e acesso às condições de trabalho, saúde, cultura e lazer e com alto índice de adoecimento em face das relações e condições de trabalho e, também, em decorrência das inúmeras batalhas cotidianas. Prevalece, portanto, uma tendência de profundo empobrecimento das condições objetivas e subjetivas, que apesar do amplo desenvolvimento das forças produtivas, a maioria da população não tem acesso ao que de melhor a humanidade tem produzido do ponto de vista material e espiritual, caracterizando a complexa relação entre capitalismo, questão social e barbárie.

Assim, o entendimento crítico da particularidade da questão social no Brasil exige que façamos articulação entre três divisões que assumem dimensões estruturais e que, mediadas por inúmeras determinações, estabelecem organicidade entre si: a divisão social, fundada nas relações entre classes sociais e projetos distintos de sociedade; a divisão racial, fundada nas relações sociais de raça e a 
divisão sexual, fundada nas relações sociais e patriarcais de gênero/sexo. Isto significa que a diversidade não é uma questão específica ou de teor menor, que possamos optar por considerá-la ou não na apreensão da realidade.

Vivenciamos, portanto, uma situação de barbárie que é objetiva e subjetiva, marcada por um processo de decadência ideológica ${ }^{12}$ em que as classes dominantes disseminam, mesmo diante da crise estrutural do capital, a impossibilidade de transformação das relações sociais vigentes. Temos um arsenal teórico-metodológico que ao articular história, humanismo e razão dialética (COUTINHO, 2010) e obviamente ser apropriado e atualizado, de modo permanente, torna-se importante ferramenta para desmistificar a naturalização da desigualdade social e pôr em relevo a possibilidade da crítica radical à sociabilidade do capital e a necessidade histórica de sua própria transformação. ${ }^{13}$

É certo que a arma da crítica não pode substituir a crítica das armas, que o poder material tem de ser derrubado pelo poder material, mas a teoria converte-se em força material quando penetra nas massas. A teoria é capaz de se apossar das massas ao demonstrar-se ad hominem e, demonstra-se ad hominem logo que se torna radical. Ser radical é agarrar as coisas pela raiz [...] (MARX, 2005, p.151).

Indiscutivelmente o papel da pesquisa na produção do conhecimento crítico e no combate ao conservadorismo é um desafio fundamental. Conhecer a realidade, apreender mediações e estabelecer conexões entre os fenômenos da vida cotidiana e as determinações societárias é um caminho para a superação de todas as tendências de simplificação da realidade, a exemplo do economicismo, do politicismo e do culturalismo.

Nosso ponto de partida teórico-metodológico - a centralidade do trabalho, o que implica os indivíduos em suas relações concretas de existência - além de estabelecer profundas diferenças com os fundamentos liberais e pós-modernos, evidencia os limites do entendimento da vida social e da individualidade, quando é tomado como ponto de partida o discurso, a linguagem e as representações. Há, desse modo, uma grande lição que consiste, também, em um desafio que é superar

\footnotetext{
${ }^{12}$ Cf. o significado histórico e teórico da decadência ideológica em LUKÁCS (2010).

${ }^{13}$ Exemplo do caráter radicalmente destrutivo que assume a produção e reprodução capitalista neste momento. Em março de 2018, o IBGE divulgou que 13,7 milhões de pessoas estão desempregadas no país, recaindo sobre a população negra e em especial sobre a mulher negra, as formas mais precárias de inserção no trabalho e de mais ataque e controle sobre sua vontade subjetiva e seu corpo, por meio do assédio moral, sexual e estupro, além das iniciativas de invisibilizar e destruir suas raízes históricas e sua presença atual na vida pública em diferentes espaços.
} 
unilateralidades centradas ora na objetividade, ora na subjetividade. Apanhar a totalidade:

trata-se , pois, para Marx, de partir não das ideias, especulações ou fantasias, mas de fatos reais, 'empiricamente verificáveis', no caso os indivíduos concretos, o que eles fazem, as relações que estabelecem entre si e as suas condições reais de existência, para então apreender as determinações essenciais que caracterizam este tipo de ser e o seu processo de reprodução (TONET, 2000,p.42).

A individualidade tem lugar na reflexão crítica e de totalidade e entendê-la exige transitar entre as contradições e conflitos da relação entre sociabilidade e individuação, localizando o ser singular como ser histórico, genérico e diverso. Neste sentido, decifrar e entender as complexas relações entre o Estado, a propriedade privada e o casamento monogâmico/família monogâmica abre fronteiras para a ruptura com concepções idealistas na elaboração da concepção da subjetividade e da própria diversidade, tidas ambas, neste campo teórico, como algo que existe nas trilhas internas dos indivíduos, como uma espécie de mundo interior, que supostamente não tem vínculo com as relações sociais vigentes. De outro modo, na perspectiva da totalidade, a essência dos indivíduos está no conjunto das relações sociais e somente inseridos em suas relações concretas de existência é que podem ser apreendidos.

A auto-organização dos sujeitos é outro aspecto decisivo contra as formas simplificadoras e se diferencia da especificação de sujeitos de direitos proposta na agenda liberal, notadamente por Bobbio (1992). O ideário da especificação pressupõe reconhecimento jurídico-político de vários segmentos: mulheres, crianças, adolescentes, idosos, população negra, LGBTI, pessoas com deficiência, dentre muitos outros. Este reconhecimento legal é importante, no entanto, tal especificação levou um conjunto de autores(as) a decretar a impossibilidade objetiva da elaboração pela classe trabalhadora, em sua heterogeneidade e diversidade, de um projeto político emancipatório.

Exatamente por isso, a agenda da diversidade foi equivocadamente denominada como uma "agenda pós-moderna", que necessariamente celebra a fragmentação, cada segmento voltado para as suas reivindicações e obstaculiza a organização dos sujeitos em torno de um projeto político classista, emancipatório e voltado à defesa dos interesses da classe trabalhadora. Esse fio de articulação só é 
possível mediante o reconhecimento pelos sujeitos daquilo que os unifica na vida cotidiana. A reivindicação em face de uma expressão da sua diversidade pode ser diferente, mas estão vivenciado de forma comum quase sempre, a escassez de direitos; a violência; a inserção precária no mundo do trabalho ou o próprio desemprego e formas de violação de direitos do trabalho e em face da sua raça/etnia, orientação sexual, identidade de sexo/gênero. O mundo do trabalho tão desigual e classista é permeado pelo racismo, sexismo e LGBTIfobia.

Para finalizar, umas das grandes lições que podemos apreender da história, notadamente entre as esquerdas é o total prejuízo teórico, político e humano que as práticas sectárias causaram no percurso vivenciado até aqui. A superação das concepções restritas de diversidade - economicista, politicista, culturalista, incluindo aqui o ideário do "politicamente correto", que embora importante, restringe o respeito à diversidade ao uso de uma linguagem inclusiva - exige das esquerdas e dos sujeitos individuais e coletivos que desejam contribuir no enfrentamento do conservadorismo, capacidade de auto crítica, de profundo entendimento quanto à relevância política da articulação entre os sujeitos e as lutas sociais, em busca de desenvolvimento da unidade na diversidade.

Esta tarefa jamais foi fácil, não seria no tempo atual, em que a construção histórica de um projeto de transformação social que contemple a diversidade apresenta-se como teórica, política e humanamente necessários frente ao avanço do conservadorismo e da barbárie capitalista. Trata-se, afinal de uma sociedade que tem no seu modo de ser uma determinação fundante que é a apropriação privada da riqueza socialmente produzida e que intensifica a precarização e a superexploração da força de trabalho. É nesta perspectiva que se coloca como uma grande necessidade histórica hoje os processos de organização da resistência no enfrentamento desta sociabilidade. Fundamental, no entanto, entender que existem condições histórico-estruturais que possibilitam ou não a transformação real. Segundo Marx (1986, p.57):

Os elementos materiais de uma subversão total são, de um lado, as forças produtivas existentes e, de outro, a formação de uma massa revolucionária que se revolte, não só contra as condições particulares da sociedade existente até então, mas também contra a própria produção da vida vigente, contra a atividade vigente, contra a atividade total sobre a qual se baseia. 
Quando falamos, portanto, de um projeto de transformação social outra importante contribuição do marxismo e que também emerge como um desafio se refere à superação do verdadeiro desvio de rota vivenciado por parte significativa da esquerda em nível mundial e nas particularidades do Brasil. De acordo com Mèszáros (2002, p.21), "a criação da alternativa radical ao modo de reprodução metabólica do capital é uma necessidade urgente, mas não há de acontecer sem uma avaliação crítica do passado".

E aqui considero que o marxismo fornece por meio do seu método importantes contribuições para a superação do pragmatismo e do imediatismo das análises. Novamente é válido enfatizar que a perspectiva de totalidade na análise da vida social possibilita apanhar as múltiplas determinações e conhecer a realidade em sua densidade histórica, na perspectiva de entender que pensar do ponto de vista de classe não significa destituir os indivíduos de sua individualidade e de sua diversidade. Assim, o conhecimento e a formação da consciência de classe exigem o entendimento e a consciência da diversidade humana.

\section{Referências}

BOBBIO, Norberto. A era dos Direitos. Rio de Janeiro: Campus, 1992.

COSTA, Gilmaisa Macedo. Indivíduo e Sociedade: sobre a teoria da personalidade em Georg Lukács. Maceió: EDUFAL, 2007.

COUTINHO, Carlos Nelson. O estruturalismo e a miséria da razão. São Paulo: Expressão Popular, 2010.

DAVIS, Angela. Mulher, Raça e Classe. São Paulo: Boitempo, 2016.

DIAS, Edmundo Fernandes. Cidadania e racionalidade de classe. In: Universidade e sociedade. Ano VI № 11, junho, 1996.

GOLDMAN, Wendy. Mulher, Estado e Revolução. São Paulo: Boitempo: Iska Edições, 2014.

GREEN, James N. Além do carnaval: a homossexualidade masculina no Brasil do século XX. São Paulo: Editora UNESP, 2000.

KERGOAT, Danièle. Dinâmica e consubstancialidade das relações sociais". In : Novos Estudos. CEBRAP, n. 86, março 2010. 
LUKÁCS, Georgy. Marxismo e teoria da literatura. São Paulo: Expressão Popular, 2010.

MARX, Karl. A ideologia Alemã. São Paulo: Hucitec, 1986.

. Crítica da filosofia do direito de Hegel. São Paulo: Boitempo, 2005.

MÉSZÁROS, István. Para Além do Capital. Tradução de Paulo Sérgio Castanheira e Sérgio Lessa. São Paulo: Boitempo Editorial; Editora da UNICAMP, 2002.

Marxismo e direitos humanos. In: Filosofia, ideologia e ciência social: ensaios de negação e afirmação. São Paulo: BOITEMPO, 2008.

NETTO, José Paulo. Capitalismo e Reificação. São Paulo: LECH, 1981.

RODRIGUES, Julian. Direitos Humanos e diversidade sexual: uma agenda em construção. In: VENTURINI, Gustavo \& BOKANY, Vilma. Diversidade Sexual e Homofobia no Brasil. São Paulo: Editora Fundação Perseu Abramo, 2011.

SAFFIOTI, Heleieth. Gênero, patriarcado, violência. São Paulo: Perseu Abramo, 2004.

SANTOS, Silvana M. M. desigualdade e diversidade. In: BOSCHETTI, Ivanete (at all). Política Social no capitalismo: tendências contemporâneas. São Paulo: Cortez, 2008.

- Política Social e diversidade humana: crítica à noção de igualdade de oportunidade. In: BOSCHETTI, Ivanete (at all). Capitalismo em crise: política social e direitos. São Paulo: Cortez, 2010.

. Diversidade sexual: fonte de opressão e de liberdade no capitalismo.

In: Revista Argumentum, Vitória, v. 9, n. 1, p. 8-20, jan./abr. 2017.

SILVA, Andréa Lima \& SANTOS, Silvana M. M. O legado do marxismo na análise do direito à cidade e da diversidade sexual. IN: BOSCHETTI, Ivanete; BEHRING, Elaine \& LIMA, Rita de Lourdes (Orgs.) Marxismo. Política Social e direitos. São Paulo: Cortez, 2018.

SCHENEIDER, Graziela (Org.). Emancipação Feminina na Rússia Soviética. São Paulo: Boitempo, 2017.

TONET, Ivo. Para além dos direitos humanos. Maceió: UFAL, 2000 (mimeo). Lukács, 2013.

Método científico: uma abordagem ontológica. São Paulo: Instituto

Recebido em: 22 de fevereiro de 2019. Aceito em: 06 de maio de 2019. Publicado em: 28 de maio de 2019. 